\title{
The Collapse Accident Analysis for Steel Structure of Waste-heat Boiler in a Cement Plant
}

\author{
Zaihua Zhang ${ }^{1,2,}$, Xingping Shu ${ }^{1}$, Zhishen Yuan ${ }^{3}$ and Ran $\mathrm{He}^{1,2}$ \\ ${ }^{1}$ Steel Structural Institute of Civil Engineering College, Hunan University, Hunan, 410082, P.R. China \\ ${ }^{2}$ Department of Civil Engineering, Hunan City University, Hunan, 413000, P.R. China \\ ${ }^{3}$ College of Civil Engineering and Mechanics, Central South University of Forestry and Technology, Hunan, 410004, \\ China, P.R. China
}

\begin{abstract}
By means of on-site investigation, inspection, interior experiments, theoretical analysis and calculation, a detailed analysis is carried out on the cause of the partial collapse accident about a waste-heat boiler steel structure in a cement plant of Hunan province of China. The results of inspection and analysis show that: as a key part of load transfer, the connection weld of long thin steel plate is poor in quality, meanwhile, the detail of beam-column connection can not meet the requirement of rigid joint stipulated by the design, which are the main causes for the collapse accident of boiler steel structure. Based on the analysis of accident cause, some problems worthy of consideration are put forward to the design and construction of this kind of structure, such as the weld procedure and quality control of long thin steel plate connection weld, etc.
\end{abstract}

Keywords: Collapse accident, detail of beam-column connection, inspection and analysis, long thin steel plate connection weld, waste-heat boiler steel structure.

\section{INTRODUCTION}

Boiler steel structure is a kind of special steel structure form [1,2]. Usually it can bear big load, and the distributions of mass and rigidity of the whole system are very uneven, which hardly has any complete floor. Meanwhile, the changes of floor height are very big. It is a typical flexible structure, and some improper measures during the design, construction and usage could lead to engineering accident. In this paper, the partial collapse accident of a waste-heat boiler steel frame in a cement plant is analyzed and identified. Through the identification and analysis, the process and the causes of the accident have been revealed. At the same time, some problems are put forward which are worthy of thinking seriously about during the design and construction of the same type of engineering.

\section{OVERVIEW OF THE PROJECT}

The waste heat boiler structure system is located in Hunan province of China. It is a set of equipment which recovers heat from the discharged high temperature gas of cement plant to produce power. Tube-box shape structure is adopted in this power generating boiler. There are several tube chambers arranged from bottom to top, including dustsettling compartment, super-heater tube chamber of high

\footnotetext{
*Address correspondence to this author at the Steel Structural Institute of Civil Engineering College, Hunan University, Hunan, 410082, P.R. China; Tel: 0737-4628311; Fax: 0737-4628773; E-mails: zaihua_zhang@163.com; 598813932@qq.com
}

pressure period, evaporator tube chamber of high pressure period, super-heater tube chamber of low pressure stage, evaporator tube chamber of low pressure stage, economizer tube of low pressure stage and the sharing of economizer. All of these tube-boxes are fixed on the steel beams of the main steel structure through the base of each tube chamber.

The boiler steel structure is a single span braced-frame steel structure: the span $4.6 \mathrm{~m}$, the inter-column distance $7 \mathrm{~m}$ $\mathrm{x} 3+3.5 \mathrm{~m}$, 6-storey with total height of $30 \mathrm{~m}$. The structure is designed considering seismic precautionary intensity of 8 , site of Class II [3], and the basic wind pressure is 0.45 $\mathrm{kN} / \mathrm{m}^{2}$. The project was completed in March 2011. The steel column adopted welded box section, and the steel beam adopted $\mathrm{H}$ section or welded box section according to the load size. The first to third storey were dust-settling compartments, the fourth floor was super-heater tube chamber of high pressure segment. The dust-settling compartment and super- heater tube chamber of high pressure segment were welded together as a combination. Through the base of super-heater tube chamber, the combination was installed on the steel beams of the third floor. Fig. (1) shows the structure layout of the boiler steel structure

As can be seen from Fig. (1), the dust-settling compartment and super- heater tube chamber was connected into a whole through $4 \mathrm{~mm}$ fillet weld. The composite unit was hung onto the steel beams of the third floor. Meanwhile, considering the off-center of the mass centre and the point of 


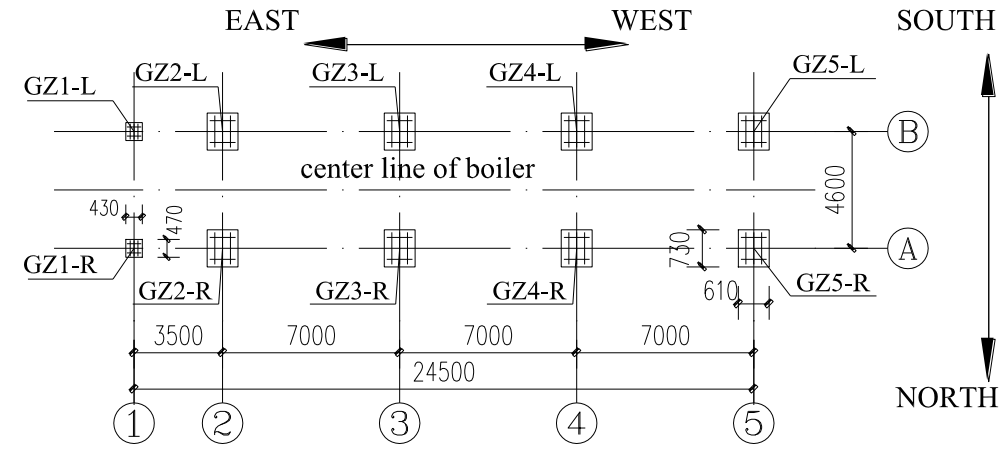

(a) Plan of the steel column layout

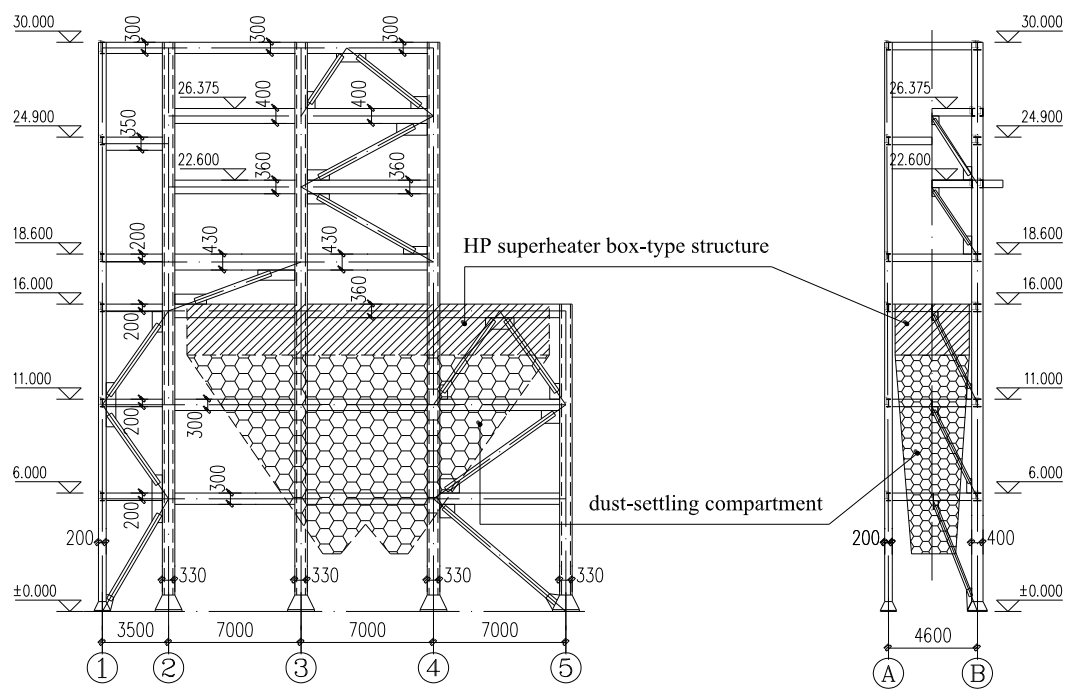

(b) Vertical plan of structure layout

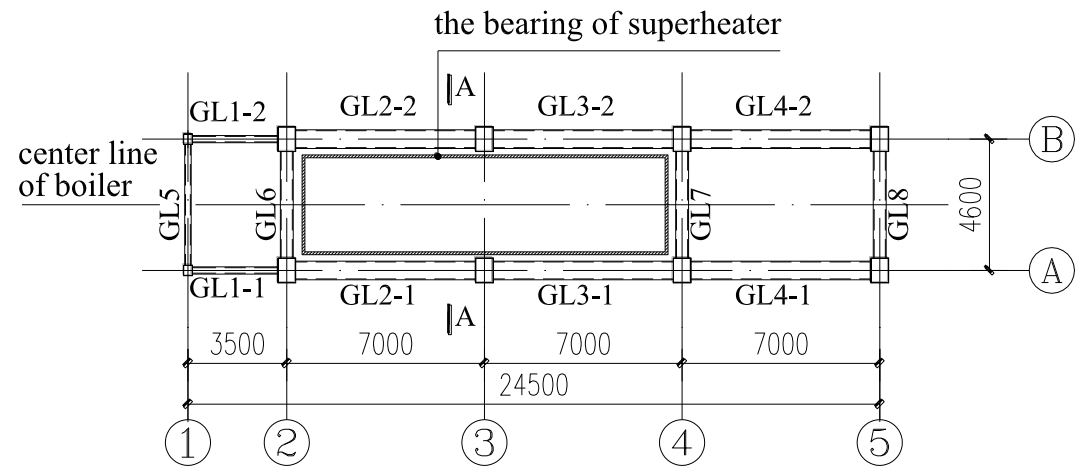

(c) Layout plan of the third floor beams

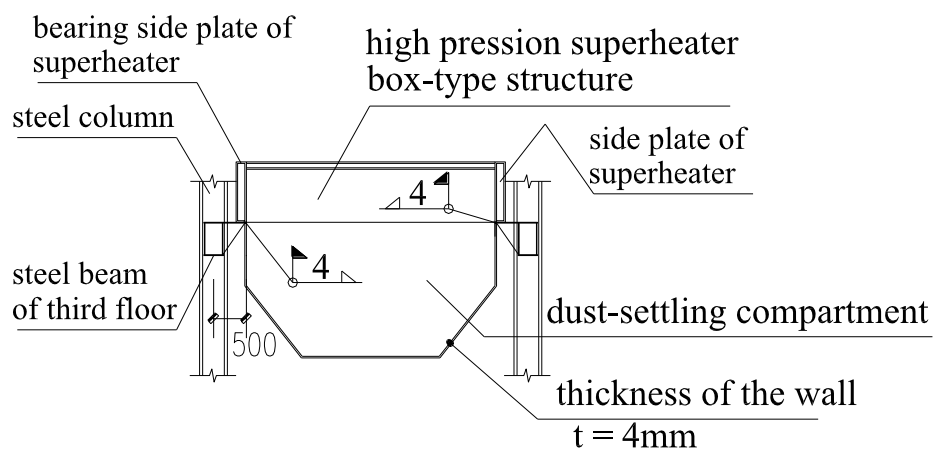

(d) A-A profile details

Fig. (1). Structure layout of the boiler steel structure. 
bearing reaction resultant, the combination was actually in a state of cantilever.

\section{ACCIDENT REASON ANALYSIS}

\subsection{Accident Synopsis}

About 13:40 p.m., July 16, 2012, the combination of dust-settling compartment and super-heater tube chamber suddenly collapsed. Fig. (2) shows the main scene of the accident situation. The dust-settling compartment has fallen to the ground inclined and formed an angle, east high and west low (Fig. 3). The eastern end of the super-heater tube chamber of high pressure period was still suspended on the steel beam, while western end has sunk into the dust-settling compartment completely (Fig. 4), and parts of the connection welds between the dust-settling compartment and superheater tube chamber were torn open completely (Fig. 5). At the same time, the bearing beams of third floor have been distorted seriously, and the damage of beam-column joints was obvious (Figs. 6, 7).

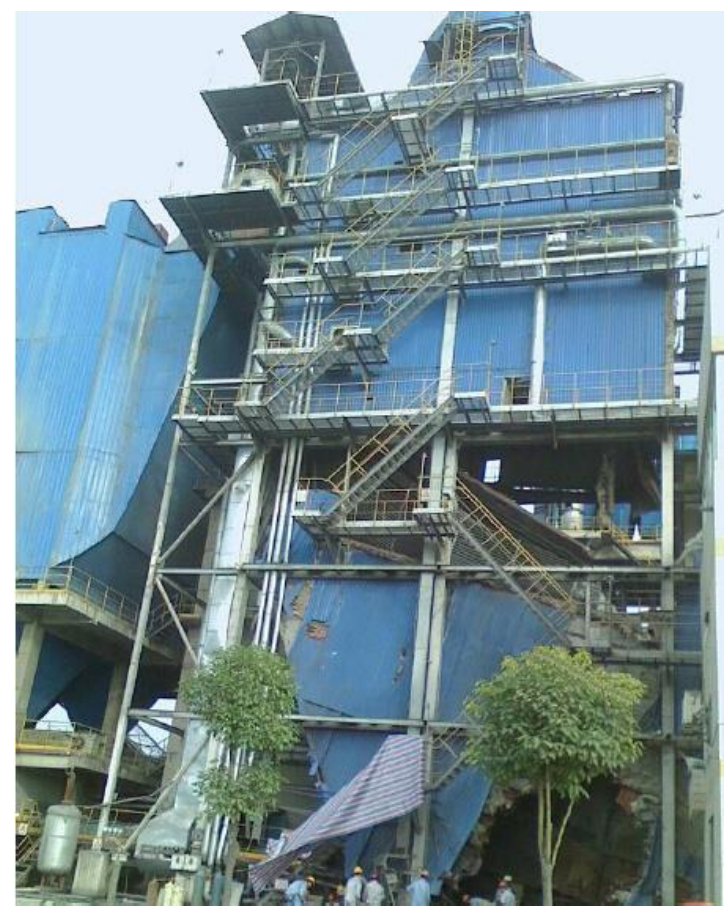

Fig. (2). The main scene of the accident.

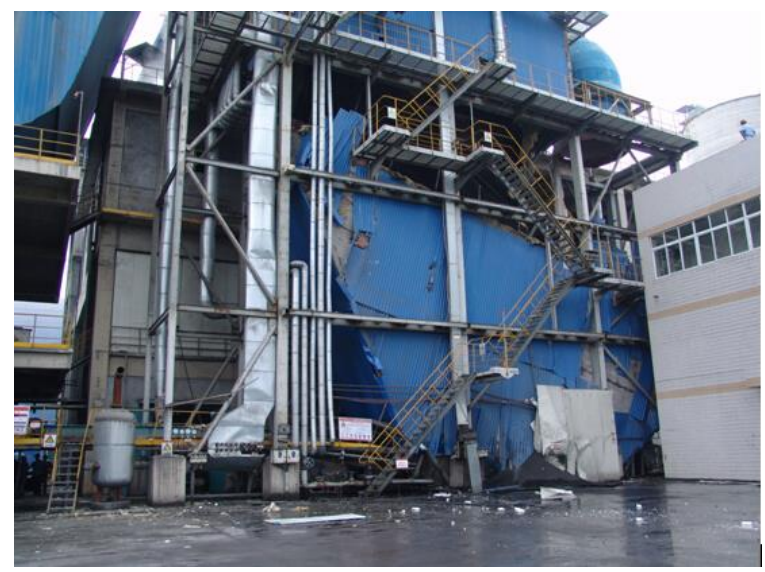

Fig. (3). Collapse of dust-settling compartment.

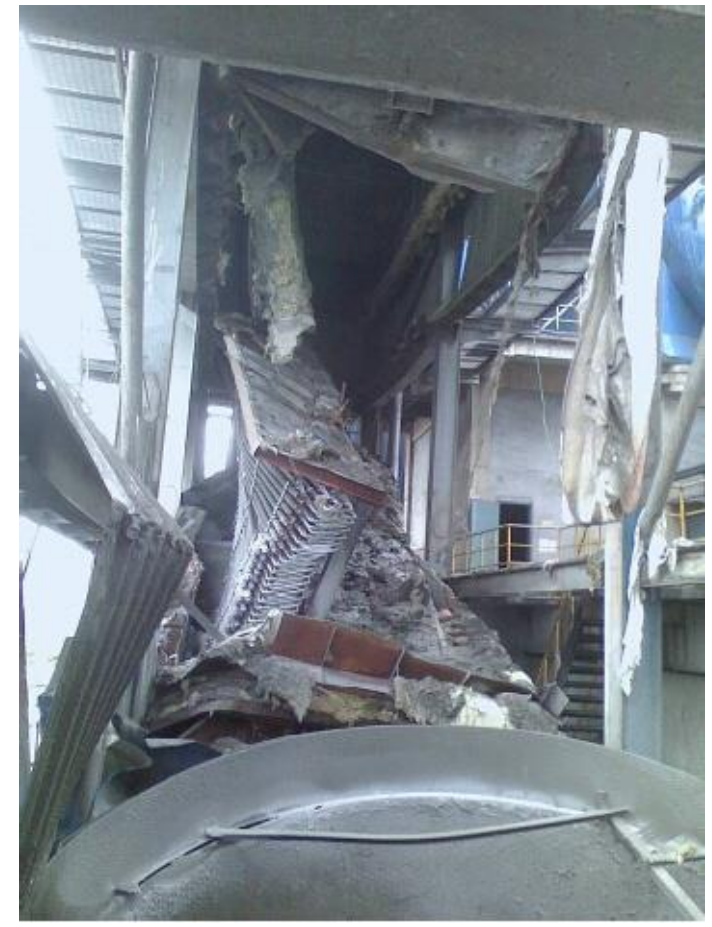

Fig. (4). Collapse of super-heater tube chamber.

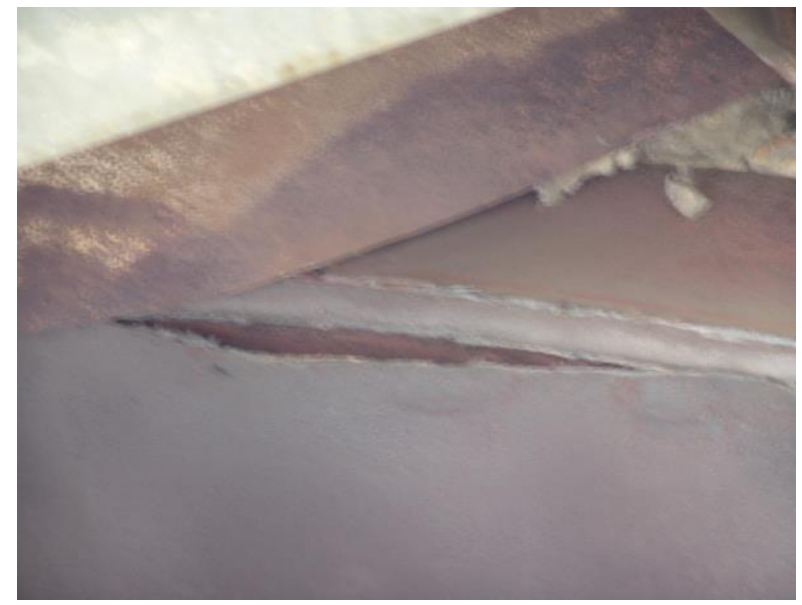

Fig. (5). Tearing seam between the attachment weld.

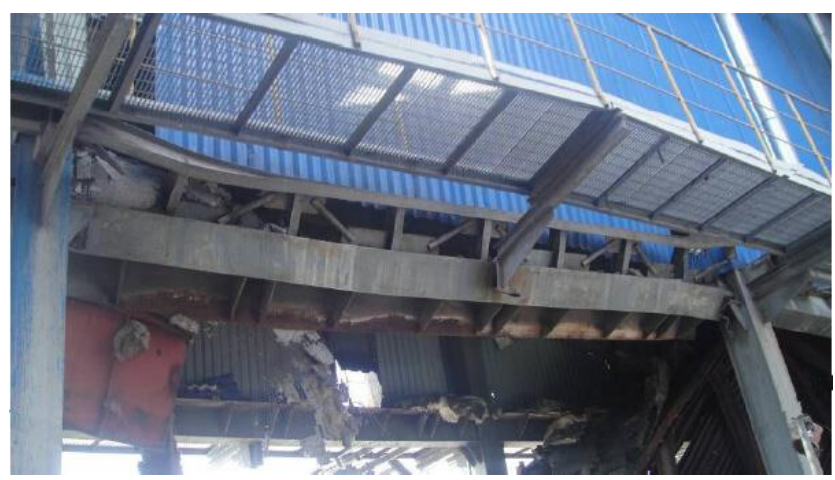

Fig. (6). Distortion of bearing beam.

After the accident, the deposition in the dust-settling compartment has been removed. The total weight of the deposition reaches about 198.9 tons, with a volume of $165.72 \mathrm{~m}^{3}$. 


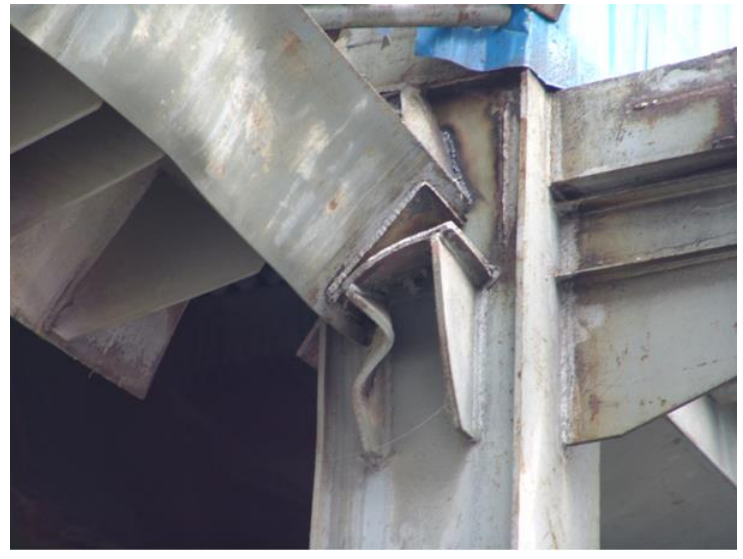

Fig. (7). Damage of beam-column joint.

\subsection{Investigation, Inspection and Analysis}

In order to find out the cause of the accident, a comprehensive investigation was conducted to the current situation of the boiler steel structure, emphasizing on inspecting the structure, whole performance, connection details and welding quality. Meanwhile, the bearing capacity of the key connections and components is checked.

\subsubsection{Inspection of Steel Mechanical Properties}

Plain carbon structural steel Q235A is adopted in the design of the boiler steel structure. Test specimen is extracted from the damage components of the boiler steel structure to inspect the steel mechanical properties. The test result shows the steel plate used in the structure meets the requirements of steel grade Q235A according to the stipulation of Carbon structural steels（GB/T 700-2006） [4].

\subsubsection{Structure Whole Tilt Inspection}

Topcon GTS332N-type total station is adopted to inspect the structure's verticality situation on spot. The measure point arrangement is shown in Fig. (8), and Table $\mathbf{1}$ shows the inspection results. The results indicate that the maximum relative displacement of measure point is $40 \mathrm{~mm}$ (the value of measure point $2 \#$ ), which exceeds the value of 35 , but does not exceed 45(a limit value prescribed by GB50144-2008 [5]). The value has exceeded the prescribed limits of GBT22395-2008 (specification for design of boiler steel structures) $(H / 500=16000 / 500=32 \mathrm{~mm})$ [4]. Accor-ding to the item 7.3.9 of Standard for appraisal of reliability of industrial buildings and structures (GB50144- 2008) [6], the ratings of frame displacement is graded as B-degree, which has a limited impact on the normal application of the structure.

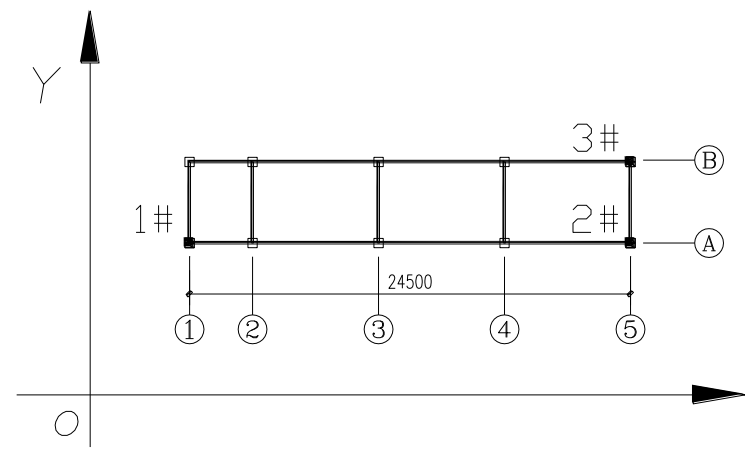

Fig. (8). Verticality Observation Measure Point Arrangements.

\subsubsection{Weld Quality Inspection}

The boiler steel structure is a full welded structure. The site investigation shows that the structure was extensively damaged in many connection welds. During on-site examination, comprehensive weld inspection was carried out, including appearance inspection and ultrasonic flaw detection.

\section{(1) Appearance Inspection of Weld Quality}

The appearance quality inspection of the main connection welds in the structure was conducted. The inspection results indicated that there were numerous deficiencies about the connection weld of the structure, mainly including the several types as follows (See Fig. 9): (a) leakage solder, (b) insufficient weld length, (c) poor visual quality, (d) serious corrosion.

\section{(2) Ultrasonic Detection of Weld Quality}

The column of this boiler steel structure adopted boxsection. Vertical splice of column section is butt weld connection. Fig. (10) illuminates the splice detail of column section. Ultrasonic detection was adopted to evaluate the welding quality, and a total of 36 segments of butt weld seam was inspected. The result shows that for all of inspected weld, 35 segments were qualified and there was only one weld omitted (See Fig. 9a).

\subsubsection{Re-checking of Weld Strength for the Connection of the Dust-Settling Compartment and Super-Heater Tube Chamber}

Fillet weld has been adopted for the connection between dust-settling compartment and super-heater tube chamber, full-welded along the bonding pad, and the size of weld is $4 \mathrm{~mm}$. According to the actual arrangement situation of the weld, we can draw the weld plan as shown in Fig. (11).

Table 1. Measured results of lateral displacement of the structure.

\begin{tabular}{|c|c|c|c|}
\hline Measuring point & The height of measuring point to ground/m & Offset in X direction/mm & Offset in Y direction/mm \\
\hline \hline $1 \#$ & 30 & 22 & - \\
\hline $2 \#$ & 16 & - & 40 \\
\hline $3 \#$ & 16 & - & 30 \\
\hline
\end{tabular}




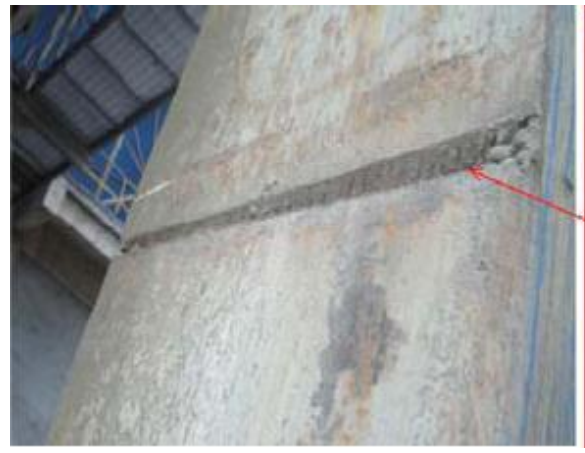

GZ4L:

at the

place of

elevation

$12 \mathrm{~m}$

(a) Column flange butt-weld leakage solder
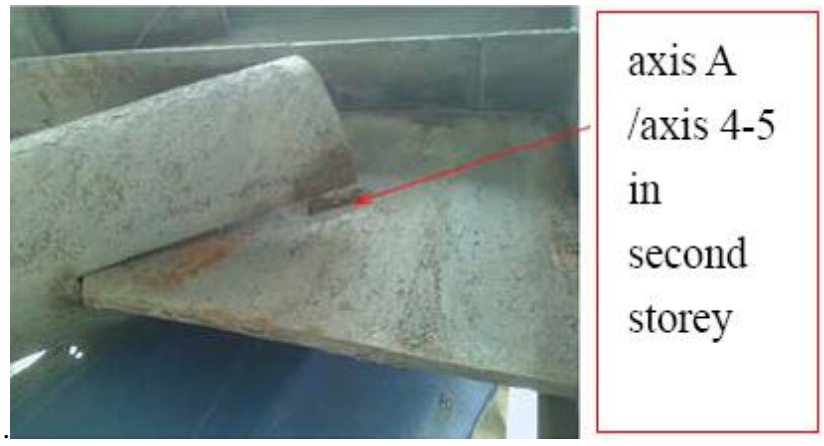

(b) Insufficient weld length in tube-gusset plate connections

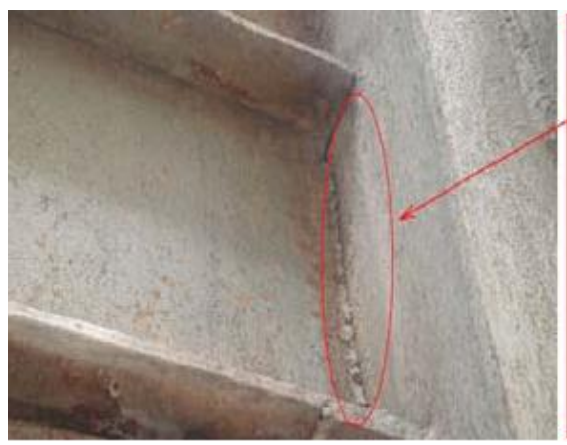

GZ5R:

beam-

column

connection

in second

storey

(c) Poor visual quality about fillet weld

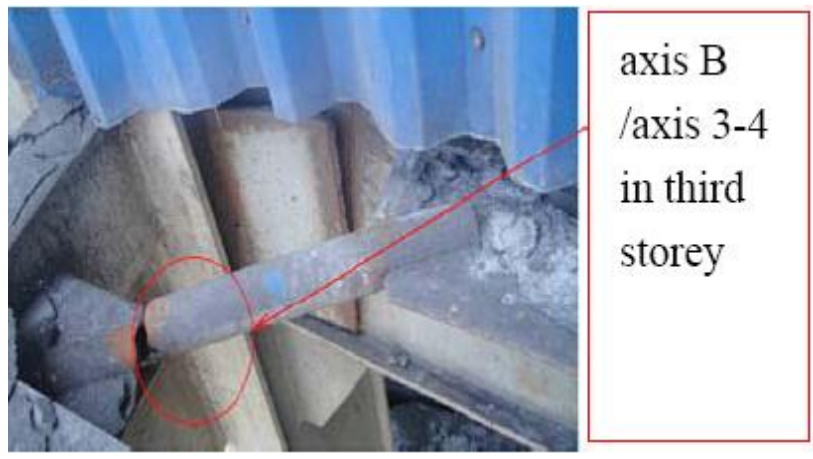

(d) Serious corrosion leading to breakage of horizontal bracing Fig. (9). Appearance defects of the connection weld.

Checking the design drawing of the dust-settling compartment, the self-weight $\left(N_{G K}\right)$ of this equipment is 38.835 tons. As mentioned above, the total weight of the deposition $\left(N_{Q K}\right)$ in the dust-settling compartment is 198.8 tons. So, we can get the design value of actual load $(N)$ about the connection (ignoring the uneven distribution of the deposition):
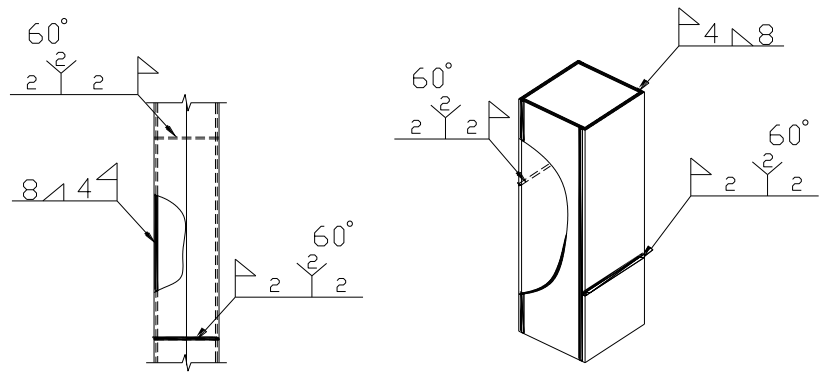

Fig. (10). Splice detail of the column section.

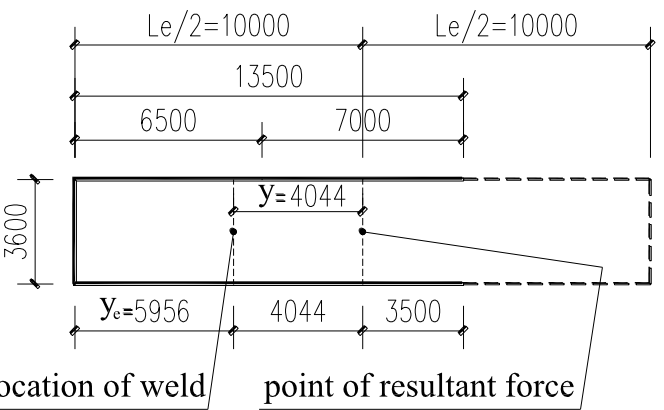

Fig. (11). Arrangement of the weld.

$$
\begin{aligned}
N & =\gamma_{G} N_{G k}+\gamma_{Q} N_{Q k}=1.2 \times 388.35+1.4 \times 1989 \mathrm{kN} \\
& =3250.62 \mathrm{kN}
\end{aligned}
$$

Where, $\gamma_{G} 、 \gamma_{Q}$ is the partial safety factor of permanent load and variable load, respectively.

The checked weld is transverse fillet weld, and its centroid location is shown in Fig. (11). Ignoring the uneven distribution of the deposition and the construction error and defect, we can regard that the resultant point of load get through the centroid of dust-settling compartment. Obviously, the two centroids are not coincidence, and the checked section of weld is under the situation of eccentric tension.

The distance between weld centroid and the left end of weld is:

$$
\begin{aligned}
y_{e} & =\frac{\sum A_{i} y_{i}}{\sum A_{i}} \\
& =\frac{3600 \times 2.8+2 \times 13500 \times 2.8 \times 6750}{3600 \times 2.8+2 \times 13500 \times 2.8} \\
& =5956 \mathrm{~mm}
\end{aligned}
$$

And the eccentric distance from the point of resultant force to the centroid of weld is:

$e=20000 / 2-5956=4544 \mathrm{~mm}$

Where, $L_{e}$ is the long sides of the top size of the dust-settling compartment (See Fig. 11). So, we can get the inner force of the weld section: 


$$
\begin{aligned}
N & =3250.62 \mathrm{kN} \\
M & =N e=3250.62 \times 4.544 \mathrm{kN} \cdot \mathrm{m} \\
& =14770.82 \mathrm{kN} \cdot \mathrm{m}
\end{aligned}
$$

The geometric feature values of weld section are as follows:

$$
\begin{aligned}
A & =h_{e} l_{w}=0.7 \times 4 \times(13500 \times 2+3600) \mathrm{mm}^{2} \\
& =85680 \mathrm{~mm}^{2} \\
I_{y} & =2 \times \frac{b h^{3}}{12}+A_{1} y_{c}^{2} \\
& =2 \times \frac{2.8 \times 13500^{3}}{12}+2.8 \times 3600 \times 6750^{2} \\
& =1.607 \times 10^{12} \mathrm{~mm}^{4} \\
W_{y} & =\frac{I_{y}}{y}=\frac{1.607 \times 10^{12}}{13500-5956}=2.13 \times 10^{8} \mathrm{~mm}^{3}
\end{aligned}
$$

The maximum tensile stress is located in the left side of the weld section, and it is the most dangerous point of the section. We can get the stress state of dangerous point:

The axial tensile stress:

$\sigma_{f}^{N}=\frac{N}{A}=\frac{3250.62 \times 10^{3}}{85680}=37.93 \mathrm{~N} / \mathrm{mm}^{2}$

Bending normal stress :

$\sigma_{f}^{M}=\frac{M_{y}}{W_{y}}=\frac{14770.82 \times 10^{6}}{2.13 \times 10^{8}}=69.35 \mathrm{~N} / \mathrm{mm}^{2}$

And the total normal stress is :

$$
\begin{aligned}
\sigma & =\sigma_{f}^{N}+\sigma_{f}^{M}=37.93+69.35=107.28 \mathrm{~N} / \mathrm{mm}^{2} \\
& <\beta_{f} f_{f}^{w}=1.22 \times 160 \mathrm{~N} / \mathrm{mm}^{2}=195.2 \mathrm{~N} / \mathrm{mm}^{2}
\end{aligned}
$$

Where, the parameter $\beta_{f}$ is the strength coefficient for transverse fillet weld, and $f_{f}^{w}$ is the strength design value of fillet weld.

From the above calculation, we can see that, without considering the construction error and defect, the connection weld between dust-settling compartment and super-heater tube chamber is safety. Weld stress is less than the standard limit.

\subsubsection{Carrying Capacity Re-Checking for the Bearing Beam of Super-Heater Tube Chamber}

According to structure arrangement of the third floor, we can get the distribution diagram of load for the bearing beam of super-heater tube chamber as shown in Fig. (12). All bearing beams have the same section (See Fig. 13). In the site of accident, we can see that the bearing beams twisted seriously while the columns have little damage. So, it is necessary to re-check the carrying capacity of bearing beam.
GL2-2
GL3-2

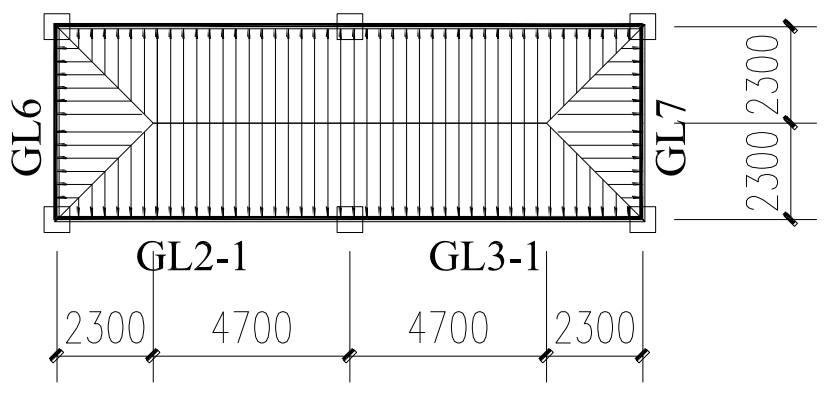

Fig. (12). Distribution diagram of load for bearing beam.

The weight of dust in the dust-settling compartment is 198.8 tons, the self-weight of the dust-settling compartment and super-heater tube chamber are 38.835 tons and 30.587 tons respectively. All loads were passed to the bearing beam through the super-heater supports (See Fig. 13), so, we can get the characteristic value of the uniformly distributed load for the bearing beam: dead load $24.8 \mathrm{kN} / \mathrm{m}$, live load 71 $\mathrm{kN} / \mathrm{m}$. At the same time, a uniformly distributed twisted moment is also loaded on it, considering eccentric effect of the loading.

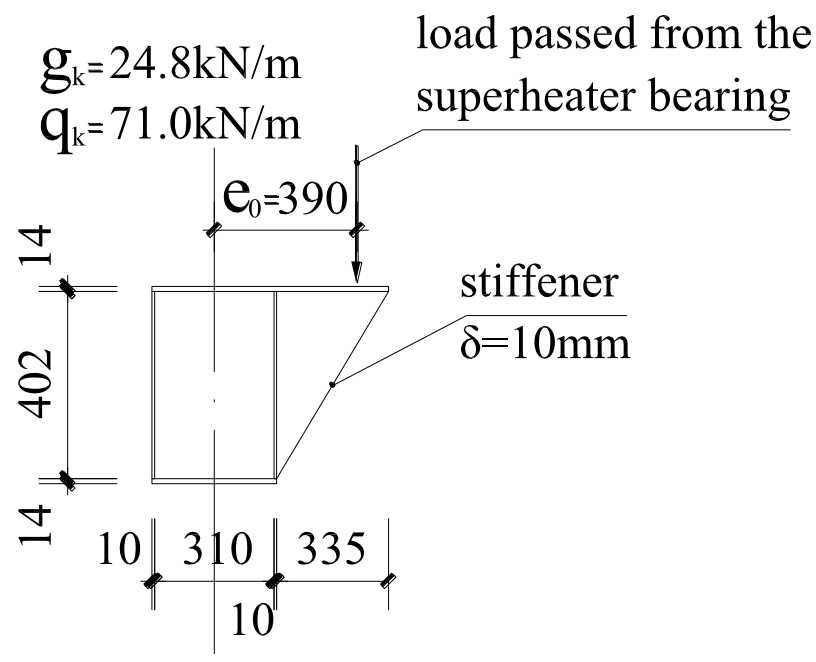

Fig. (13). The section of bearing beam and its bearing load.

3D3S 3 dimension steel structure system (developed by Tongji University) was used to check the bearing beam GL3, which is under the most unfavorable load. Fig. (14) shows the design details of beam-column connection, it can be regarded as a rigid connection. Table 2 gives the basic section geometrical parameter, and the sketch of load distribution and structure analysis can be seen in Fig. (15).

Table 2. Section geometrical parameter GL3.

\begin{tabular}{|c|c|c|c|}
\hline Box-section & Section area/mm & Inertia moment turning around axis $\mathbf{2} /\left(\mathbf{x 1 0} \mathbf{~ m m}^{\mathbf{4}}\right)$ & Inertia moment turning around axis $\mathbf{3} /\left(\mathbf{x 1 0} \mathbf{~ m m}^{\mathbf{4}}\right)$ \\
\hline \hline 430x330x10x14 & 17280 & 19970 & 50818 \\
\hline
\end{tabular}


Table 3. The check result of stress ratio and deformation for bearing beam GL3.

\begin{tabular}{|c|c|c|c|c|}
\hline Bending strength & Shear strength & Overall stability turning around axis 2 & Overall stability turning around axis $\mathbf{3}$ & Mid-span deflection \\
\hline \hline 0.97 & 0.42 & 0.97 & 0.97 & $1 / 1384$ \\
\hline
\end{tabular}

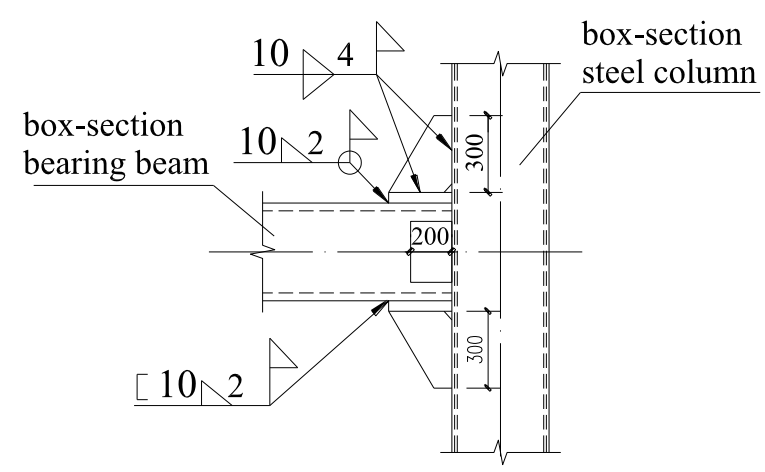

Fig. (14). Design details of beam-column connection.

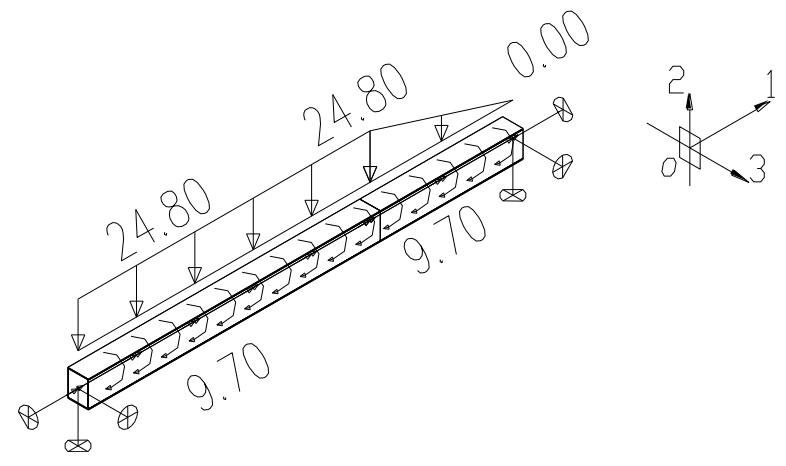

(a) Distribution sketch of dead load

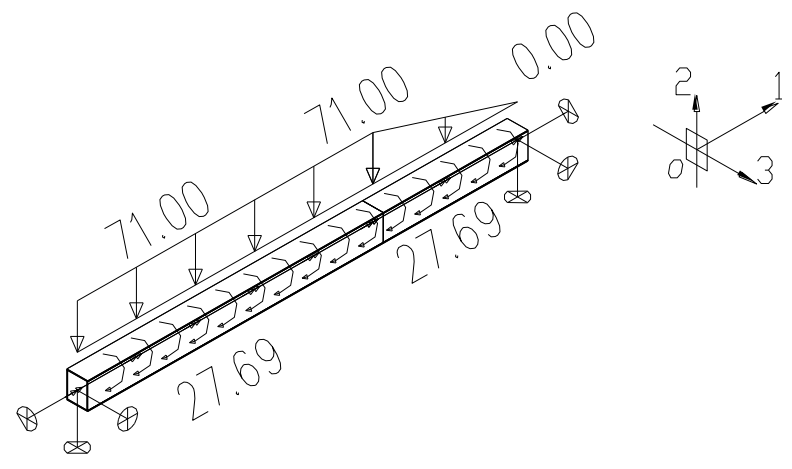

(b) Distribution sketch of live load

Fig. (15). Sketch of load for GL3.

Table 3 shows the check result of bearing beam GL3. It can be seen that both the section strength and overall stability stress ration are less than 1.0 , and the mid-span deflection 1/1384 is less than the maximum permissible limit $1 / 850$, pursuant to the stipulation of Section 5.15 of GBT22395-2008(specification for design of boiler steel structures), that is to say, under the actual uniform line load and uniform torque, the bearing beam GL3 is safety from the design perspective. But one thing is worthy to be pointed out, the above analysis are based on the assumptions of beam-column rigid connection. At the scene of the accident, we found that the actual detail of beam-column was shown in Fig. (16). Obviously, it doesn't meet the requirements of rigid assumptions.

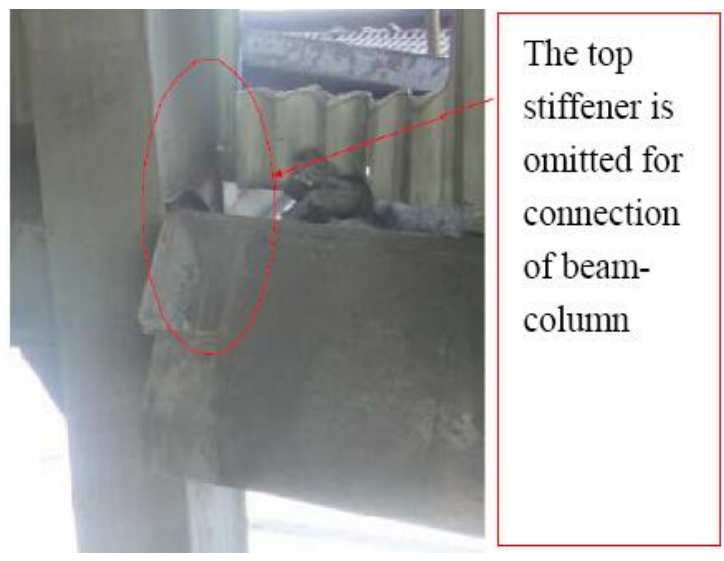

Fig. (16). The actual details of beam-column.

\section{CONCLUSION}

\section{Accident Process and the Root Cause}

Based on the field survey, inspection and calculation analysis, we summarize the collapse process of dust-settling compartment and super-heater tube chamber as following: Under the weight of dust, western cantilever part of dustsettling compartment drooped firstly, then, northern part of the connection weld between dust-settling compartment and super-heater tube chamber was torn out and northern part of the dust-settling compartment dropped to the ground. After the north side connection weld was broken, all loads were borne by the steel beam of the south and both sides of east and west, while the load area of south steel beam is the largest, resulting in the twisted failure of south steel beam, also leading to the super-heater supported on the beam to drop into the dust-settling compartment.

According to the design check, the connection weld between dust-settling compartment and super-heater tube chamber should be safe under the existing load. But the weld was found to fail in several places. The poor weld quality is the root cause for the failure of connection weld. The wall thickness of dust-settling compartment is only $4 \mathrm{~mm}$, and the requirement of welding is quite high. However, most of the welds were actually discontinuous and the sizes of welds are uneven. When the local peak stress is caused by the weld defect exceeds the weld strength, the weld crack will appear. Under the action of long-time load, the weld crack continuously develops, and eventually the whole weld tears damage, causing the appearance of collapse accident.

\section{Appraisal Conclusion}

Based on the results of inspection and calculation analysis, we can get some conclusions as follows: 
I. The mechanical properties of steel plate conform to the requirements of steel grade $\mathrm{Q} 235 \mathrm{~A}$ according to the stipulation of Carbon structural steels (GB/T 700-2006).

II. After the collapse accident, the verticality deviation of the whole structure has exceeded the prescribed limits of GBT22395-2008. According to the rule of Standard for appraisal of reliability of industrial buildings and structures (GB50144-2008), the horizontal displacement ratings is graded as B-degree, which has a limited impact on the normal application of the structure.

III. Under the load of self-weight of equipment and the actual load, the design of the connection weld among dust-settling compartment, super-heater tube chamber and the bearing beams of the third floor is safety.

IV. The quality of fillet weld of this boiler steel structure is poor, the detail of beam-column connection for the collapsed parts of the structure does not meet the requirements of design drawing, which are the key factors to induce the accident.

V. With the exception of the omitted weld (Fig. 9a), the construction quality of the butt weld for the steel column splice meets the requirements of grade II weld according to the stipulation of JG/T 203-2007(Method for ultrasonic testing and classification for steel structures) [7].

\section{Some Problem Deserved Thinking About}

Through the investigation and analysis of the collapse accident, we can find some problems deserved our attention:

I. The problem of welding processing and quality inspection for long thin plate: In the collapsed boiler steel structure, the wall thickness of dust-settling compartment is only $4 \mathrm{~mm}$, while the length of connection weld reaches $30.6 \mathrm{~m}$. As a key part of load transfer, the welding processing and quality inspection of this kind of weld should pay sufficient attention.

II. The problem of connection detail for dust-settling compartment and super-heater tube chamber: Considering the difficulty of weld for such a kind of long thin plate, a more convenient and reliable way of connection should be considered during the design process. The assembly method showed in Fig. (17) should be a better way suitable for such a situation.

III. The problem of beam-column details: Compared to the main components such as beam and column, the connection of beam-column seems to be important, but the details of beam-column affect the analysis model of structure and component directly. Random changes to the details of beam-column should be banned during the construction process.

IV. The problem how to prevent overload for closed container: In the condition of use, the dust-settling

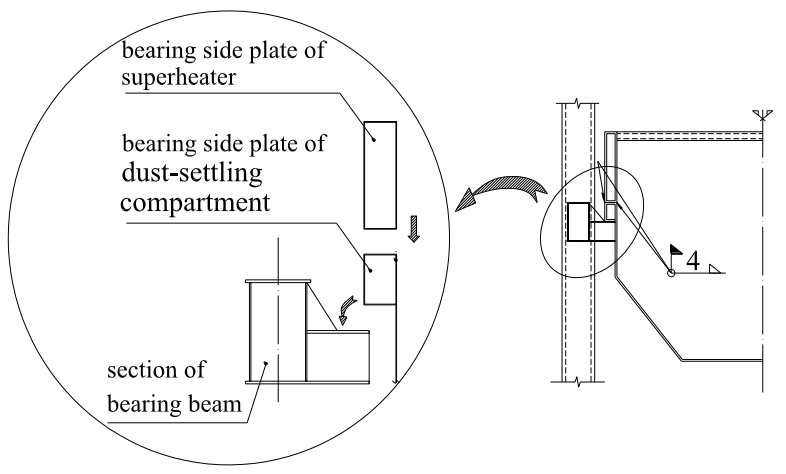

Fig. (17). A improved detail for the connection of dust-settling compartment and super-heater tube chamber.

compartment is a closed container, and it is unknown whether the deposition in the dust-settling compartment has exceeded the limitation or not. So, it is necessary to add a monitoring device to prevent overload of dustsettling compartment.

\section{CONFLICT OF INTEREST}

The authors confirm that this article content has no conflicts of interest.

\section{ACKNOWLEDGEMENTS}

The research work was supported by the Natural Science Fund of Education Department of Hunan province (Grant No. 14C0212、10C0213), National Natural Science Foundation of China under Grant No. 50978089.

\section{REFERENCES}

[1] X. C. Jia, "A Study on Mechanical Behavior of Tower-type Boiler Steel Structure", M.S. thesis, Shanghai Jiao Tong University, Shanghai, China, 2010. (in Chinese).

[2] Y. M. Dong, J. G. Chen, and H. Xie, "Concept of Boiler Truss Static Calculation and Load (Acting) Effect", Boiler Technology, vol. 33, pp. 14-22. 2002.

[3] GB 50011-2010, “Code for Seismic Design of Buildings", Prepared by the Ministry of Housing and Urban-Rural Development of China. Beijing, 2010, p. 20. (in Chinese).

[4] GB/T 700-2006, "Carbon Structural Steels", Prepared by the China National Standardization Management Committee, Beijing, 2006, pp. 2-4. (in Chinese).

[5] GBT22395-2008, "Specification for Design of Boiler Steel Structures", Prepared by the China National Standardization Management Committee, Beijing, 2006, p. 7. (in Chinese).

[6] GB50144-2008, "Standard for Appraisal of Reliability of Industrial Buildings and Structures", Prepared by the Ministry of Housing and Urban-Rural Development of China, Beijing, 2008, p. 38. (in Chinese).

[7] JG/T 203-2007, "Method for Ultrasonic Testing and Classification for Steel Structures", Prepared by the Ministry of Housing and Urban-Rural Development of China, Beijing, 2007, p. 12. (in Chinese).

This is an open access article licensed under the terms of the Creative Commons Attribution Non-Commercial License (http://creativecommons.org/licenses/by-nc/3.0/) which permits unrestricted, non-commercial use, distribution and reproduction in any medium, provided the work is properly cited. 